\title{
Complications of labial minor salivary gland biopsy and comparison of complications in patients with and without primary Sjögren's syndrome
}

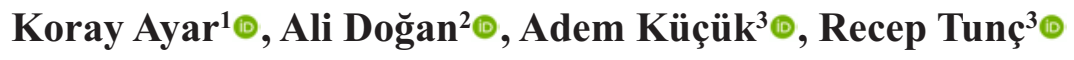 \\ ${ }^{1}$ Department of Rheumatology, University of Health Sciences, Bursa Yüksek Ihtisas Training and Research Hospital, Bursa, Turkey \\ ${ }^{2}$ Department of Internal Medicine, Adlyaman University, Training and Research Hospital, Adiyaman, Turkey \\ ${ }^{3}$ Department of Rheumatology, Necmettin Erbakan University, Meram Faculty of Medicine, Konya, Turkey
}

\begin{abstract}
Objectives: Labial minor salivary gland biopsy (MSGB) is a procedure in which complications such as bleeding, hematoma, numbness, wetness can be seen after the procedure. It is not known whether these complications have changed in patients with primary Sjögren's syndrome (PSS). The aim of this study is to investigate the frequency of complications after the labial MSGB and to investigate whether these complications has changed in PSS.

Methods: Participants with a preliminary diagnosis of PSS who underwent a labial MSGB without any suture were included in the study. One month after the procedure, the complication screening questionnaire was administered face-to-face interview or by telephone. All complications were compared between PSS and nonPPS groups.

Results: Complications screening questionnaire was applied to 99 participants (face to face with 79 participants and by telephone with 20 participants). After the procedure, $17.2 \%$ of the participants had uncomfortable bleeding, $2.0 \%$ had persistent numbness which continues more than 1 week and $1.0 \%$ had wetness and hematoma. Bleeding duration was more than 1 hour in $11.1 \%$ of the participants. Complications were not different between PSS and non-PSS groups $(p>0.05)$.

Conclusions: After the labial MSGB procedure without suturing, uncomfortable bleeding is frequent and the duration of bleeding is long, but complications other than bleeding are rare. The incidence of complications after labial MSGB procedure was not different in participants with PSS than in those without PSS.

Keywords: Complications, labial minor salivary gland biopsy, primary Sjögren's syndrome
\end{abstract}

$\mathrm{P}$ rimary Sjögren's syndrome (PSS) is a chronic autoimmune inflammatory disorder characterized by diminished lacrimal and salivary gland function. Saliva has many useful functions in the mouth, such as; antimicrobial effect, tissue repair and protection [1]. Degreased saliva may cause traumatic lesions and may increase oral mucosal infections due to decreased antimicrobial effect $[2,3]$. Thrombocytopenia and acquired hemophilia may occur in PSS, which may cause bleeding tendency $[4,5]$. Minor salivary gland biopsy (MSGB) is a widely used procedure with high diagnostic value in the classification of PSS [6]. Minor

How to cite this article: Ayar K, Doğan A, Küçük A, Tunç R. Complications of labial minor salivary gland biopsy and comparison of complications in patients with and without primary Sjögren's syndrome. Eur Res J 2020;6(5):508-516. DOI: 10.18621/eurj.743915

Address for correspondence: Koray Ayar, MD., Assistant Professor, University of Health Sciences, Bursa Yüksek Ihtisas Training and Research Hospital, Department of Rheumatology, Bursa,Turkey.E-mail:drbartu@gmail.com 
salivary gland biopsy is usually performed from the labial region, but can also be done from the sublingual region [7]. Labial MSGB can be performed with different methods at different centers, for example, the procedure can be completed with or without suture, or incision can be performed vertically or horizontally $[8$, 9]. In literature, there are few studies evaluating complications after labial MSGB [7, 8, 10, 11]. Although the incidence of complications after the procedure is low in these studies, complications such as persistent paresthesia, hematoma, local wetting may be seen [10, 11]. Lip is a tissue with intense blood circulation and bleeding can be expected after incisions. There is no information in the literature about how long the bleeding continues after labial MSGB procedure. There may be clinical conditions in SS that may have the potential to increase the complications of labial MSGB. There is no study in the literature comparing the complications of labial MSGB in patients with and without SS. In this study, we aimed to determine the biopsy complications in which the bleeding time is evaluated in detail following labial MSGB and we aimed to compare biopsy complications between patients with and without SS.

\section{METHODS}

Ethics committee approval of the study was obtained from Necmettin Erbakan University (NEU) Clinical Research Ethics Committee. The study included volunteers from the NEU medical faculty of rheumatology department who were planned to undergo a labial MSGB procedure to investigate the etiology of sicca symptoms and subsequently underwent the procedure. Demographic data and preexisting diseases of all participants after the labial MSGB procedure were recorded.

\section{Labial minor salivary gland biopsy}

In our center, LSGB procedure is applied to all patients with a standard procedure. All labial MSGB procedures were performed by two investigators. The procedures of all participants were performed in semi-

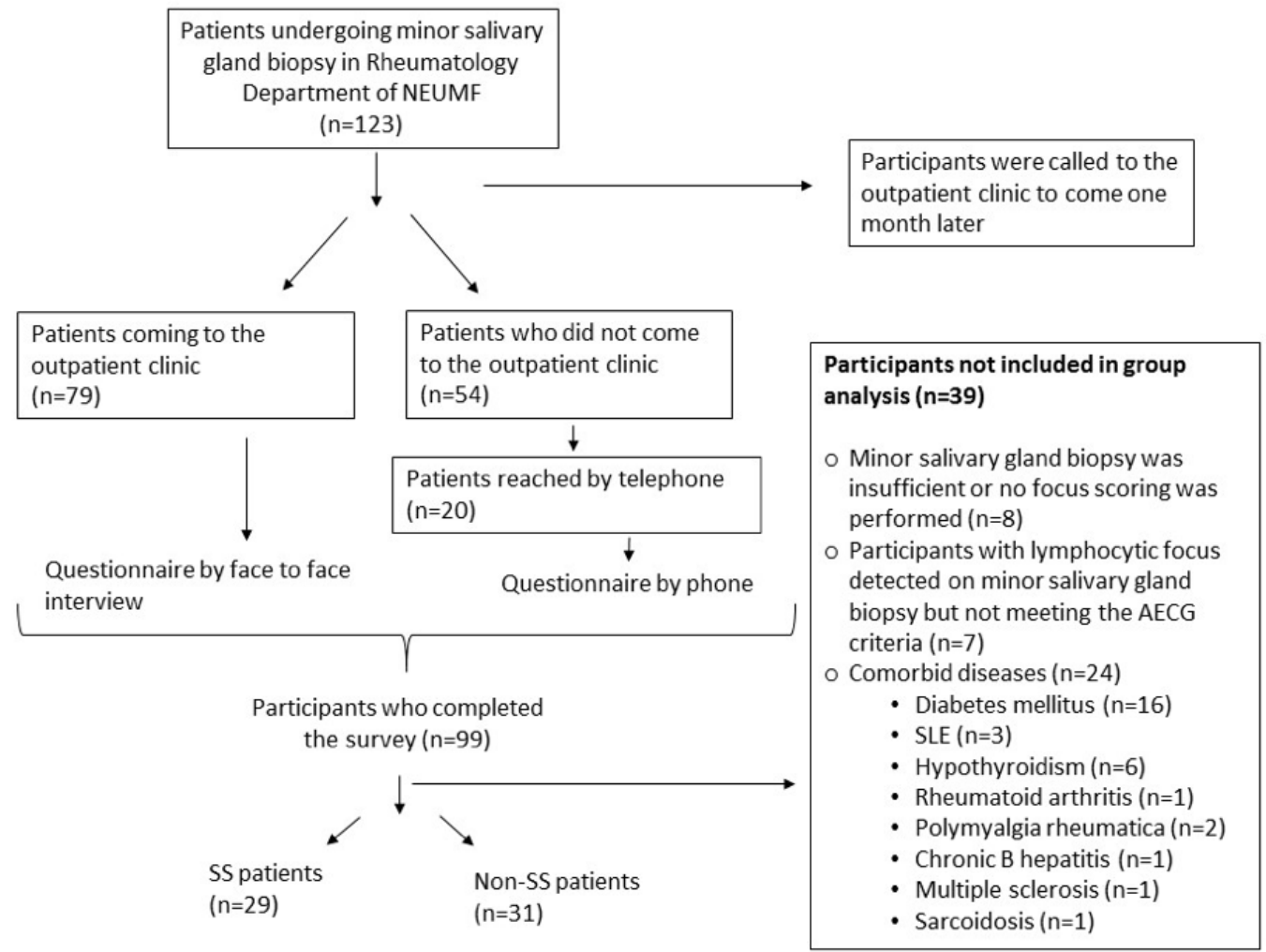

Fig. 1. A flow chart showing the number of the participants included in the study at all stages and the exclusion reasons of the participants excluded from the study. 
fowlers position and local anesthesia was applied to all participants before the procedure. The incisions of the participants were applied vertically to the $2 \mathrm{~cm}$ square area on the right or left side of the inner lip midline with a length of 5-10 mm. Forceps was used for blunt dissection and excision of the minor salivary glands of all participants. In each labial MSGB procedure, at least 2 samples of 1-3 mm3 were collected, each with several minor salivary gland tissues. Biopsy wounds were left to heal spontaneously without any sutures. After the procedure was completed, the participant was instructed to apply 10 minutes of compression with a sterile sponge.

\section{Histopathology of minor salivary gland biopsy}

Labial MSGB specimens were consulted with the pathology department. Of the 99 samples included in the study, 1 was reported as insufficient material, 7 had no lymphocytic focus scoring, and all other samples' lymphocytic focus scorings were reported as described by Chisholm et al. [6].

\section{Complication screening survey}

After the labial MSGB procedure, participants were called to the outpatient clinic for 1 month later. Complications screening questionnaire (CSQ) was applied face to face to the participants who came to outpatient clinic control. Participants who underwent biopsy but did not come to the outpatient clinic control after 1 month were called by telephone and the CSQ was performed on the telephone. The CSQ consists of 13 questions. In 8 of the questions, the participants were questioned about the presence of complications after labial MSGB procedure and the participants were asked to answer the questions as yes, no or I don't remember. In 5 of the questions, how long the complication after MSGB procedure persists was asked to the participants. The questions of the CSQ are shown in Table 1.

\section{Group analysis}

Symptoms of dry mouth and dry eye, presence of objective dry eye, ANA, anti-Ro (SSA) and anti-La (SSB) test results of all participants with lymphocytic focus (grade 3-4) on MSGB were recorded from patient charts [6]. Patients diagnosed with SS according to the American-European Consensus Group (AECG) classification criteria were included in the
PSS group [12]. Participants without lymphocytic focus on minor salivary gland biopsy were included in the non-PSS group. Participants with systemic disease, diabetes mellitus, hypothyroidism, chronic hepatitis, and those who did not have lymphocytic focus scoring in the salivary gland biopsy and who had insufficient MSGB material were not included in the group analysis. The number of the participants included in the study at all stages and the exclusion reasons of the participants excluded from the study are summarized in a flow chart in Fig. 1.

\section{Statistical Analysis}

SPSS Version 22.0 for Windows (SPSS Inc, Chicago, IL, USA) was used to process all data statistically. Variables are presented as mean, median, standard deviation (SD), minimum-maximum or frequency. To compare quantitative variables, Mann-Whitney U-test was used. For the comparison of qualitative data, $\chi^{2}$ test or Fischer's exact $\chi^{2}$ test was used. All tests were two-tailed, and $p$ values $<$ 0.05 were considered to indicate statistical significance.

\section{RESULTS}

Complication screening questionnaire was applied to 99 participants (12 male, 87 female). Demographic data, pathological scoring of minor salivary gland biopsies and comorbid diseases of the participants who have completed the CSQ are summarized in Table 2. Answers of the participants who have completed the CSQ are shown in Table 1. Sixty participants were included in the group analysis, 29 of them were included in the PSS group and 31 were included in the non-PSS group. Sicca symptoms, ocular signs, autoantibody tests and MSGB histopathology results of participants included in PSS group are shown in Table 3. The answers of the participants in the PSS and non-PSS groups to the questions in the CSQ and the comparison of the answers between the groups are shown in Table 4.

\section{DISCUSSION}

In this study, we investigated the incidence of 
Table 1. Answers of the participants who have completed the complication screening questionnaire

\section{Questionnaires}

Data

1) Did you feel pain during the procedure? (yes/no/don't remember)

$21 / 78 / 0$

2) Was there any bleeding that would disturb you after the biopsy? (yes/no/don't

$17 / 82 / 0$ remember)

3) How long was the bleeding period?, n (\%)

$\begin{array}{lc}<10 \text { minutes } & 56(56.6) \\ 10-30 \text { minutes } & 19(19.2) \\ 31-60 \text { minutes } & 13(13.1) \\ 61 \text { minutes-3 hours } & 9(9.1) \\ >3 \text { hours } & 2(2.0) \\ \text { you have trouble eating after the biopsy? (yes/no/don't remember) } & 16 / 81 / 2\end{array}$

4) Did you have trouble eating after the biopsy? (yes/no/don't remember)

$<7$ days

$\geq 14$ days

6) Was there any persistent numbness around the lip after the biopsy? (yes/no/don't

$10 / 89 / 0$ remember)

7) How many days did the numbness persists around the lip?, n (\%)
$<7$ days
7-14 days
$\geq 14$ days
$0(0.0)$
8) Was there a feeling of wetness in the mouth after biopsy? (yes/no/don't
$1 / 98 / 0$ remember)

9) How many days did the wetness in the mouth persist after the biopsy?, n (\%)

$$
\begin{array}{cc}
<7 \text { days } & 1(100.0) \\
7-14 \text { days } & 0(0.0) \\
\geq 14 \text { days } & 0(0.0) \\
10) \text { Was there any blood collection (hematoma) in the lip after the procedure? } & 1 / 98 / 0
\end{array}
$$
(yes/no/don't remember)

11) Was there an infection at the incision site after the procedure? (yes/no/don't remember)

$0 / 99 / 0$

12) How many days did the incision heal?, n (\%)

$\begin{array}{lc}<7 \text { days } & 88(88.9) \\ 7-14 \text { days } & 7(7.1) \\ \geq 14 \text { days } & 3(3.0) \\ \text { Don't remember } & 1(1.0) \\ \text { here any scar after the incision has healed? (yes/no/don't remember) } & 6 / 93 / 0\end{array}$


Table 2. Demographic data, results of minor salivary gland biopsies and comorbid diseases of the participants who have completed the complication screening questionnaire

\begin{tabular}{|cc}
\hline Demographic characteristics & Data \\
\hline Age (years), mean \pm SD & $49.76 \pm 13.12$ \\
\hline Female, $\mathbf{n}(\%)$ & $87(87.9)$ \\
\hline Pathological scoring of minor salivary gland biopsy, n (\%) & \\
\hline Grade 0 & $12(12.1)$ \\
\hline Grade 1 & $18(18.2)$ \\
\hline Grade 2 & $17(17.2)$ \\
\hline Grade 3 & $21(21.2)$ \\
\hline Grade 4 & $23(23.2)$ \\
\hline No Chisholm scoring & $7(7.1)$ \\
\hline Insufficient material & $1(1.0)$ \\
\hline Comorbid diseases, $\mathbf{n}$ (\%) & \\
\hline Primary Sjögren's syndrome & $33(33.3)$ \\
\hline Secondary Sjogren's syndrome & $1(1.0)$ \\
\hline Systemic lupus erythematosus & $4(4.0)$ \\
\hline Rheumatoid arthritis & $1(1.0)$ \\
\hline Polymyalgia rheumatica & $2(2.0)$ \\
\hline Multiple sclerosis & $1(1.0)$ \\
\hline Sarcoidosis & $1(1.0)$ \\
\hline Chronic B hepatitis & $2(2.0)$ \\
\hline Diabetes mellitus & $18(18.2)$ \\
\hline Thyroid disease & $6(6.1)$ \\
\hline
\end{tabular}

ASA $=$ acetyl salicylic acid, $\mathrm{SD}=$ standard deviation

Table 3. Sicca symptoms, ocular signs, autoantibody tests and MSGB histopathology results of participants included in primary Sjögren syndrome group

\begin{tabular}{lccc}
\hline \multicolumn{1}{c}{$(\mathbf{n = 2 9 )}$} & Positive & Negative & Not known/not performed \\
\hline Oral symptoms, n (\%) & $26(89.7)$ & $3(10.3)$ & $0(0.0)$ \\
Ocular symptoms, n (\%) & $23(79.3)$ & $6(20.7)$ & $0(0.0)$ \\
\hline Ocular signs $^{1}, \mathrm{n}(\%)$ & $22(75.9)$ & $3(10.3)$ & $4(13.8)$ \\
ANA, n (\%) & $20(69.0)$ & $9(31.0)$ & $0(0.0)$ \\
Anti-Ro (SSA), n (\%) & $10(34.5)$ & $12(41.4)$ & $7(24.1)$ \\
Anti-La (SSB), n (\%) & $6(20.7)$ & $16(55.2)$ & $0(0.0)$ \\
\hline Histopathology ${ }^{2}, \mathrm{n}(\%)$ & $29(100.0)$ & $0(0.0)$ & \\
Grade 3 & $15(51.7)$ & & \\
Grade 4 & $14(48.3)$ & & \\
\hline ANA & & & \\
\hline
\end{tabular}

ANA $=$ anti-nuclear antibodies, Ro/SSA = anti-Sjögren's syndrome antigen A, La/SSB = anti-Sjögren's syndrome antigen B, MSGB = minor salivary gland biopsy, ${ }^{1}$ Schirmer's test or Rose-Bengal or other ocular dye test, ${ }^{2}$ lymphocytic focus on minor salivary gland biopsy [6] 
Table 4. Demographic data of PSS and non-PSS groups and their answers to the questions in the complication screening questionnaire

\begin{tabular}{|c|c|c|c|}
\hline & $\begin{array}{c}\text { Non-PSS } \\
(\mathrm{n}=\mathbf{3 1})\end{array}$ & $\begin{array}{c}\text { PSS } \\
(\mathrm{n}=29)\end{array}$ & $p$ value \\
\hline Age (years), median (mimimum-maximum) & $48.00(24-81)$ & $48.00(25-72)$ & 0.739 \\
\hline Female, n $(\%)$ & $24(77.4)$ & $27(93.1)$ & 0.148 \\
\hline \multicolumn{4}{|l|}{ Complication screening questionnaire } \\
\hline $\begin{array}{l}\text { 1) Did you feel pain during the procedure? (yes/no/don't } \\
\text { remember) }\end{array}$ & $9 / 22 / 0$ & $8 / 21 / 0$ & 1.000 \\
\hline $\begin{array}{l}\text { 2) Was there any bleeding that would disturb you after } \\
\text { the biopsy? (yes/no/don't remember) }\end{array}$ & $8 / 23 / 0$ & $2 / 27 / 0$ & 0.082 \\
\hline 3) How long was the bleeding period?, n (\%) & & & 0.775 \\
\hline 10 minutes & $15(48.4)$ & $18(62.1)$ & \\
\hline $10-30$ minutes & $7(22.6)$ & $6(20.7)$ & \\
\hline $31-60$ minutes & $5(16.1)$ & $3(10.3)$ & \\
\hline 61 minutes- 3 hours & $3(9.7)$ & $1(3.4)$ & \\
\hline$>3$ hours & $1(3.2)$ & $1(3.4)$ & \\
\hline $\begin{array}{l}\text { 4) Did you have trouble eating after the biopsy? } \\
\text { (yes/no/don't remember) }\end{array}$ & $6 / 25 / 0$ & $5 / 23 / 1$ & 0.574 \\
\hline \multicolumn{4}{|l|}{ 5) How many days did the trouble persist?, n (\%) } \\
\hline$<7$ days & $5(83.3)$ & $5(100)$ & \\
\hline 7-14 days & $1(16.7)$ & $0(0.0)$ & \\
\hline$\geq 14$ days & $0(0.0)$ & $0(0.0)$ & \\
\hline $\begin{array}{l}\text { 6) Was there any persistent numbness around the lip } \\
\text { after th biopsy? (yes/no/don't remember) }\end{array}$ & $2 / 29 / 0$ & $2 / 27 / 0$ & 1.000 \\
\hline \multicolumn{4}{|c|}{ 7-) How many days did the numbness persists around the lip?, n (\%) } \\
\hline$<7$ days & $2(100.0)$ & $2(100.0)$ & \\
\hline 7-14 days & $0(0.0)$ & $0(0.0)$ & \\
\hline$\geq 14$ days & $0(0.0)$ & $0(0.0)$ & \\
\hline $\begin{array}{l}\text { 8) Was there a feeling of wetness in the mouth after } \\
\text { biopsy? (yes/no/don't remember) }\end{array}$ & $1 / 30 / 0$ & $0 / 29 / 0$ & 1.000 \\
\hline \multicolumn{4}{|c|}{ 9) How many days did the wetness in the mouth persist after the biopsy?, n (\%) } \\
\hline$<7$ days & $1(100)$ & $0(0)$ & \\
\hline $7-14$ days & $0(0.0)$ & $0(0.0)$ & \\
\hline$\geq 14$ days & $0(0.0)$ & $0(0.0)$ & \\
\hline $\begin{array}{l}\text { 10) Was there any blood collection (hematoma) in the lip } \\
\text { after the procedure? (yes/no/don't remember) }\end{array}$ & $1 / 30 / 0$ & $0 / 29 / 0$ & 1.000 \\
\hline $\begin{array}{l}\text { 11) Was there an infection at the incision site after the } \\
\text { procedure? (yes/no/don't remember) }\end{array}$ & $0 / 31 / 0$ & $0 / 29 / 0$ & 1.000 \\
\hline 12) How many days did the incision heal?, n (\%) & & & 0.750 \\
\hline$<7$ days & $27(87.1)$ & $25(86.2)$ & \\
\hline 7-14 days & $3(9.7)$ & $2(6.9)$ & \\
\hline$\geq 14$ days & $1(3.2)$ & $1(3.4)$ & \\
\hline Don't remember & $0(0.0)$ & $1(3.4)$ & \\
\hline $\begin{array}{l}\text { 13) Is there any scar after the incision has healed? } \\
\text { (yes/no/don't remember) }\end{array}$ & $1 / 30 / 0$ & $2 / 27 / 0$ & 0.606 \\
\hline
\end{tabular}

PSS = primary Sjögren's syndrome, ASA = acetyl salicylic acid, $\mathrm{SD}=$ standard deviation 
complications following a labial MSGB procedure and compared the incidence of complications in a group of patients with and without PSS. According to the results we obtained, the most common complaint of the participants was that they felt pain during the procedure and $21.2 \%$ of the participants had pain during the procedure even though all the participants had local anesthesia before the procedure. In our study, we do not have any information about the amount of local anesthetic injected into the area before the procedure and how long to wait and perform the procedure after local anesthesia. This result may be related to the lack of effective local anesthesia. The second most common problem the participants complained of was bleeding, which was disturbing the participants after the procedure, which was seen in $17.2 \%$. In addition, 11 of 99 participants $(11.1 \%)$ who underwent labial MSGB procedure had post-operative hemorrhage lasting longer than 1 hour and 2 of them had bleeding lasting longer than 3 hours. Moreover, hematoma developed in one patient after labial MSGB. In the study of Caporali et al., hematoma was reported in 8 $(1.6 \%)$ of 502 participants who underwent labial MSGB procedure, suture was performed after procedure and the frequency of hematoma was similar to that in this study (\%1.0) [11]. In the study of Friedman et al. [8], Minor bleeding was detected in 2 of 118 participants who underwent labial MSGB, but no information was given about whether suture was performed or not in the participants with minor bleeding. To the best of our knowledge, there is no data in the literature regarding the duration of bleeding after labial minor salivary gland biopsy and, according to the information obtained from this study, bleeding after the labial MSG procedure may cause a significant proportion of patients to feel uncomfortable. Wound healing after the labial MSGB procedure can be completed with or without sutures. However, in the procedures completed by suturing, complications other than bleeding such as local wetness, local infection, and cheloid formation can be seen [8]. Another common complaint in this study was the difficulty in eating after the procedure and was present in $16.2 \%$ of the participants. Although the complaints of the majority of the participants who had difficulty eating were less than 1 week (87.5\%), 1 of 99 participants stated that his complain lasted longer than 2 weeks. There is little data on the difficulty of eating after the labial MSGB procedure. In the study of Saruhanoğlu et al. [9], labial MSGB procedure was performed with vertical incision and suture was performed after the procedure. Thirty-five (43.2\%) of 81 participants had eating difficulties after the procedure and in 4 of them, it was found that the problem of eating lasted longer than 5 days [9]. In this study, the frequency of difficulty in eating food after the procedure was lower than that of Saruhanoğlu et al. [9]. This may be related to the absence of sutures after the procedure in this study. In this study, $10.1 \%$ of the participants had persistent numbness after the procedure. However, this complaint lasted less than 1 week in $8.1 \%$ of the participants, $1-2$ weeks in $2.0 \%$ of the participants, and numbness did not persist in any of the participants for more than 2 weeks. In the study of Richards et al. [10], 58 participants underwent labial MSGB procedure and 2 participants had decreased sensation in the lips, and one patient $(1.7 \%)$ continued to have this complaint after one year. In the study of Berquin et al. [7], 16 labial MSGB procedures revealed 1 permanent lip or tongue anesthesia. In the study of Saruhanoğlu et al. [9], paresthesia was detected in 4 of 81 participants who underwent labial MSGB with vertical incision. In $1(1.2 \%)$ of these, paresthesia continued between $0-2$ months after the procedure and in 3 (3.7\%) of them 2-12 months. In all these studies, postoperative paresthesia was evaluated long after the procedure and some participants had permanent paresthesia. In this study, long-term paresthesia has not been developed in anybody and this may be related to performing the procedure without suturing. Wet sensation after the procedure was detected in only one patient in this study, this complaint did not persist after 1 week and None of the participants had post procedure-infection. In the study of Friedman et al., the complications of the sutured and non-sutured participants after the labial MSGB procedure were compared. Of the 56 sutured participants, 5 (8.9\%) had local wetting and $2(3.6 \%)$ had local infection, whereas none of the 62 non-sutured participants had local wetness or local infection. These findings from the study of Friedman et al. are consistent with the findings of this study, and suturing may increase local complications such as wetness, infection and numbness.

In this study, the frequency of biopsy complications after labial MSGB was not different between 
participants with PSS and those without PSS. In addition, postoperative bleeding times were not different between the two groups. However, although not statistically significant, the presence of bleeding to disturb participants after the procedure was less common in patients with PSS $(25.8 \%$ vs $6.90 \% ; p=$ 0.082). For some reason in PSS, participants may be less affected by the disturbing effect of bleeding. Peripheral nervous system involvement is common in PSS and varies between 2-25\% [13-15]. Peripheral cranial nerve involvement can also be seen in PSS, and even a case of glossopharyngeal and vagal nerve involvement in Sjögren syndrome has been reported in the literature $[16,17]$. In patients with PSS, less affected by the disturbing effect of bleeding may be due to the involvement of nerves involved in sensory innervation of the oral mucosa in participants with PSS. There is not enough information about this subject in the literature and further research is needed to clarify this issue.

\section{Limitations}

This study has some limitations. The number of participants included in the study was not sufficient to determine the frequency of complications of labial MSGB. Participants' self-descriptions were evaluated when evaluating post-procedure bleeding complications. In order to evaluate the amount and duration of bleeding more objectively, it would be more appropriate to observe and note the patient's bleeding time simultaneously by the investigator after the procedure. Labial MSGB procedures of the participants were performed by 2 investigators, so there may be minor differences between the two investigators in performing the procedure and this may have influenced the results.

\section{CONCLUSION}

Although postoperative complications are not common in labial minor salivary gland biopsy, some patients may have difficulty in eating after the procedure, bleeding and numbness. Bleeding may be more common in procedures performed without suturing, but complications such as infection, numbness, and wetness are very rare. The presence of underlying PSS has no effect on the complications after labial MSGB.

\section{Authors' contribution}

$\mathrm{KA}, \mathrm{AD}, \mathrm{AK}, \mathrm{RT}$ designed the study. KA and AK performed minor salivary gland biopsy procedure. $\mathrm{AD}$ applied the screening questionnaires to the participants. KA transferred the data to SPSS package program and performed statistical analysis. KA conducted a literature review and wrote the preliminary draft text. AD, AK, RT reviewed the draft text.

\section{Conflict of interest}

The authors disclosed no conflict of interest during the preparation or publication of this manuscript.

\section{Financing}

The authors disclosed that they did not receive any grant during conduction or writing of this study.

\section{REFERENCES}

1. Alhajj M, Babos M. Physiology, Salivation. StatPearls. Treasure Island (FL), 2019.

2. Carr AJ, Ng WF, Figueiredo F, Macleod RI, Greenwood M, Staines K. Sjögren's syndrome - an update for dental practitioners. Br Dent J 2012;213:353-7.

3. Thoppay JR, De Rossi SS, Ciarrocca KN. Burning mouth syndrome. Dent Clin North Am 2013;57:497-512.

4. Hay CR. Acquired haemophilia. Baillieres Clin Haematol 1998;11:287-303.

5. Zhang W, Wang F, Wang H, Hua B, Feng X, Sun L. Severe thrombocytopenia in connective tissue diseases: a single-center review of 131 cases. Clin Rheumatol 2018;37:3337-44.

6. Chisholm DM, Mason DK. Labial salivary gland biopsy in Sjogren's disease. J Clin Pathol. 1968;21:656-60.

7. Berquin K, Mahy P, Weynand B, Reychler H. Accessory or sublingual salivary gland biopsy to assess systemic disease: a comparative retrospective study. Eur Arch Otorhinolaryngol 2006;263:233-6.

8. Friedman JA, Miller EB, Huszar M. A simple technique for minor salivary gland biopsy appropriate for use by rheumatologists in an outpatient setting. Clin Rheumatol 2002;21:349-50. 9. Saruhanoglu A, Atikler M, Ergun S, Ofluoglu D, Tanyeri H. Comparison of two different labial salivary gland biopsy incision techniques: a randomized clinical trial. Med Oral Patol Oral Cir Bucal 2013;18:e851-5.

10. Richards A, Mutlu S, Scully C, Maddison P. Complications associated with labial salivary gland biopsy in the investigation of connective tissue disorders. Ann Rheum Dis 1992;51:996-7. 11. Caporali R, Bonacci E, Epis O, Bobbio-Pallavicini F, Morbini $\mathrm{P}$, Montecucco C. Safety and usefulness of minor salivary gland biopsy: retrospective analysis of 502 procedures performed at a single center. Arthritis Rheum 2008;59:714-20. 
12. Vitali C, Bombardieri S, Jonsson R, Moutsopoulos HM, Alexander EL, Carsons SE, et al. Classification criteria for Sjogren's syndrome: a revised version of the European criteria proposed by the American-European Consensus Group. Ann Rheum Dis 2002;61:554-8.

13. Pavlakis PP, Alexopoulos H, Kosmidis ML, Stamboulis E, Routsias JG, Tzartos SJ, et al. Peripheral neuropathies in Sjogren syndrome: a new reappraisal. J Neurol Neurosurg Psychiatry 2011;82:798-802.

14. Sene D, Jallouli M, Lefaucheur JP, Saadoun D, CostedoatChalumeau N, Maisonobe T, et al. Peripheral neuropathies associated with primary Sjogren syndrome: immunologic profiles of nonataxic sensory neuropathy and sensorimotor neuropathy. Medicine (Baltimore) 2011;90:133-8.

15. Brito-Zeron P, Akasbi M, Bosch X, Bove A, Perez-De-Lis M, Diaz-Lagares $C$, et al. Classification and characterisation of peripheral neuropathies in 102 patients with primary Sjogren's syndrome. Clin Exp Rheumatol 2013;31:103-10.

16. Urban PP, Keilmann A, Teichmann EM, Hopf HC. Sensory neuropathy of the trigeminal, glossopharyngeal, and vagal nerves in Sjogren's syndrome. J Neurol Sci. 2001;186:59-63.

17. Mori K, Iijima M, Koike H, Hattori N, Tanaka F, Watanabe $\mathrm{H}$, et al. The wide spectrum of clinical manifestations in Sjogren's syndrome-associated neuropathy. Brain 2005;128(Pt 11):2518-34. 